\title{
Derecho ambiental y responsabilidad social corporativa
}

\author{
José MANRIQUE LAZARTE
}

\section{RESUMEN}

Preocupación en el sector empresarial por el déficit de recursos humanos que se acrecienta para los próximos años 2013 y 2014, donde el empresariado busca fehacientemente la fórmula para cubrir tal déficit, pues gran mayoría de egresados de instituciones educativas no están obteniendo las herramientas necesarias para ser calificados y así cubrir el vacío venidero. La pregunta surge en cuanto a la solución al problema. Siendo la principal actividad la extracción de recursos naturales en el país, el déficit se enfoca por tanto principalmente allí ya que el sector minero e hidrocarburos permitirán la recepción de millonarias inversiones en los próximos años. El actual gobierno pugna por un cambio, reajuste y regulación sobre el Derecho Ambiental que ya existe en el país, pues existe un claro divorcio entre la regulación ambiental y la realidad de las industrias extractivas la cual por necesidad requiere de mayores abogados especialistas en Derecho Ambiental.

\section{INTRODUCCIÓN}

Los cambios se dan por necesidad y no por ideas. Hoy en día surge la mayor necesidad de formar cuadros profesionales especialistas en medio ambiente. E1 campo del Derecho no es ajeno a ello en absoluto, puesto que la sociedad necesita un número considerable de abogados especialistas en Derecho Ambiental, lamentablemente dichos especialistas son muy escasos en el país, al extremo que muchos abogados únicamente pretenden ingresar en el campo sin tener la especialidad ni mucho menos contar con la experiencia en manejo y gerencia ambiental. La necesidad del Derecho ambiental surge como una respuesta a la catástrofe ambiental actual en el planeta, dicha rama pretende interactuar multidisciplinariamente junto a otras disciplinas, pues no tiene eficacia por sí sola; la realidad en el país es que la materia ambiental es $80 \%$ técnica y $20 \%$ legal, por tanto, practicar el Derecho Ambiental desde la perspectiva positivista únicamente devendría en la inviabilidad de la misma. Es por esta razón que la 
polifuncionalidad de la materia haciendo sinergia con otras es la mejor manera de hacer frente a los problemas ambientales en el país.

La mejor experiencia ambiental en Perú es la minera, pues la gran minería dentro de todos los problemas y cuestionamientos ha sido la que más ha desarrollado la dinámica ambiental gracias a la tecnología de punta que maneja así como por el predominio de prácticas ambientales internacionales validadas. Esto nos hace ver la necesidad de la salubridad que representa el hecho de contar con abogados ambientalistas con experiencia minera capaces de aportar su buena práctica y experiencia en el resto de instituciones o empresas no mineras, con especial énfasis en el sector público tales como el Ministerio Público y Poder Judicial. Sin lugar a dudas, las instituciones estatales deberán aplicar experiencias del sector privado a fin de hacerse competitivas y socialmente responsables, es la única manera de lograr la eficacia en el sector público en el país. Los recursos humanos son los indicados a ejecutar tales acciones para lo cual necesitan estar altamente capacitados y preparados para así poder emprender los tan esperados cambios. Dicha preparación tiene que ver con grandes esferas: la técnica y la humana. La inteligencia emocional es el motor para que un profesional pueda tener el debido control de los asuntos ambientales, en este caso, el abogado ambientalista debe ser emocionalmente inteligente.

\section{HISTORIA DEL TÓPICO}

No hasta hace muchos años, la rama del Derecho Ambiental era desconocida en el país, primaban las tradicionales ramas tales como el Derecho Civil, Penal, laboral y Administrativo. El solo hecho de acudir a los códigos, fuentes del derecho tales como la jurisprudencia y la doctrina eran la única forma de aplicar la ley y por tanto la justicia. La dinámica social avanzaba a una velocidad tan significante que el derecho no estaba más en la capacidad de regularlo ni mucho menos controlarlo; ello ocasionaba un divorcio total entre lo académico escrito en los libros y la realidad social del país; un abogado creía que podía conseguir sus objetivos laborando solo o únicamente con algún colega, no veía la necesidad de aplicar otras herramientas ni mucho menos tener una mentalidad global y gerencial, puesto que aún predominaba el paradigma de las fronteras, de los límites, de las diferentes culturas incapaces de converger entre las mismas. La cultura de la sanción era el predominio del derecho y no de la prevención, de la planificación, organización.

En aulas universitarias, si alguien por allí y fuera de lo común respondía al momento de preguntarle por la rama que optaría por especializarse una vez culminada la profesión, que se especializaría en Derecho Ambiental o Ecológico, era objeto de interrogante o incertidumbre tal respuesta por indagar a qué se refería o lo que quería decir en realidad; pues en la universidad ni aún los 
docentes eran capaces de discernir lo que ello significaba, mientras que en otras partes del mundo el tema ya estaba avanzando desde diferentes perspectivas y realidades. Algunos docentes se inclinaban por tratar el tema desde la perspectiva del Derecho Civil; mientras transcurrían los años, cada vez era más notorio la emanación de gases contaminantes por parte del parque automotor, restaurantes y otro tipo de industria. La primera censura y enfoque fue hacia al sector minero, por lo que las comunidades campesinas y nativas empezaron a reclamar el impacto ambiental que ocasionaban las grandes corporaciones mineras, pues antes simplemente no les importaba lo que una empresa minera alrededor hiciera, ni siquiera sabían el significado de la minería en el país. Como consecuencia de la censura minera el resto del país y las instituciones empezaban a escuchar sobre el tema, más aún, la aparición del internet hizo más latente la llamada contaminación o cuidado del medio ambiente. Los paradigmas dominantes de los profesionales abogados poco a poco empezaban a cambiar, de pronto aparecían profesiones distintas al derecho que empezaban a entenderse con el medio ambiente, especialmente la profesión de la ingeniería; el derecho no podía ser más ajeno al encuentro de la ecología y así empezaban a aparecer distintas especializaciones en Derecho Ambiental tales como cursos, diplomados y otros. El punto partía que si bien los profesionales empezaban a entender la necesidad de contar con abogados ambientalistas, no se contaba con un número apreciable de especialistas en la materia, por tanto, los intentos e iniciativas por entrenar a abogados ambientalistas eran en vano e inútiles, es allí en donde se cometía el grave error de llevar el campo del Derecho Ambiental a los campos tradicionales del derecho, el resultado era nefasto, por más que existían las buenas intenciones simplemente el desconocimiento del tema y la falta de experiencia del mismo hacía inviable la calificación de los abogados inclinados a especializarse en Derecho Ambiental.

El tema ambiental pasaba a ser una verdadera moda más que un verdadero tecnicismo y gerencia en cuanto al manejo del mismo. El mercado laboral del país no tenía más remedio que contar con los profesionales aficionados o dedicados al tema puesto que eran los únicos que tenía la masa laboral peruana; ello traía como consecuencia que las empresas e instituciones muchas veces entraban en conflictos socio ambientales producto de sus recursos humanos reclutados, poco preparados en la materia, optando muchas veces por reemplazarlos una vez que estaban con los problemas encima, sin embargo no tenían mucho éxito puesto que los profesionales inexpertos seguían imperando en el mercado llegando a lo mismo; es una de las razones por las que muchas veces las instituciones y corporaciones optan por contar con profesionales extranjeros o graduados en el extranjero dada la escasez profesional doméstica.

El problema surge cuando una corporación (como ha venido sucediendo en los últimos tiempos) tiende a confundir la convivencia pacífica como resultado de la 
práctica tan común y latente de la filantropía y el asistencialismo; aún predomina el paradigma de entregar el pescado y no enseñar a pescar en la mayoría de corporaciones, situación que no es sostenible puesto que el número de conflictos sociales y ambientales han ido en aumento justamente porque aún algunas empresas insisten en dichas letales prácticas. Otro problema es el concerniente a los cuadros profesionales especialistas en dinámicas socio ambientales, tal es la escasez de dichos cuadros que muchos otros profesionales han optado por dedicarse a la materia socio ambiental más por afición que por conocimiento y experiencia o por simple intento de querer hacer las cosas bien; los resultados son muchas veces la ineficacia e inviabilidad tanto de algunas empresas como de ciertas instituciones que en gran mayoría deben entenderse hoy con asuntos socio ambientales. Urge la necesidad de formar profesionales especialistas en asuntos socios ambientales capaces de interactuar en equipos multidisciplinarios y trabajar en equipo con un liderazgo rotativo. De la misma manera en cuanto al reclutamiento de dichos profesionales especialistas, la tradicional forma por parte de las consultoras y especialistas en recursos humanos de buscar los adecuados cuadros no está más dando los resultados esperados bajo la alta complejidad y dificultad que implica contar con el correcto profesional en el momento preciso. Muchas veces es más saludable acudir a la recomendación de una buena fuente para reclutar un específico buen profesional antes que pretender evaluarlo siguiendo los mencionados parámetros y pasos tradicionalistas en la toma de personal los que generalmente ya no conllevan al adecuado reclutamiento. La Universidad Ricardo Palma ha tomado la iniciativa en la formación de cuadros profesionales especialistas en medio ambiente y asuntos sociales, pues es consciente que el capital humano es la piedra angular para hacer frente a los problemas socio ambientales que cada vez más siguen tomando fuerza en la realidad peruana. La malla curricular es una de las pocas a nivel nacional que cuenta con cursos de responsabilidad social, constituyendo éste el mejor indicador de la importancia vital que la universidad ha tomado en el tema dada la realidad regional y nacional. Mientras se sigan formando cada vez más especialistas, las empresas e instituciones en general estarán en capacidad de reclutarlos puesto que el mercado laboral y competitividad así lo exigen.

Las corporaciones asumen la responsabilidad social como una filosofía que va más allá de la ley y los convierte en aliados estratégicos de la población y las comunidades con quienes participará en la ejecución de proyectos de desarrollo sostenible; de ninguna manera pueden asumir ni mucho menos reemplazar el rol que compete al Estado, pues es allí en donde aparece el límite que de ninguna manera puede sobrepasarse a fin de no caer en las prácticas filantrópicas y asistencialistas. El problema surge muchas veces en los errores de socialización que cometen las empresas justamente por la falta de competentes cuadros profesionales mencionados líneas arriba, pues generan expectativas que no podrán cumplir y que únicamente los ayuda a mantenerse alejados de los problemas 
sociales por un momento mientras la bomba de tiempo sigue aumentando hasta que se desata el conflicto con frecuencia muy lamentable e irreparable. Generalmente el tema ambiental sirve como una excusa, como un arma frente a un conflicto social puesto que la mayor expectativa que trae una corporación es lo referente al "trabajo"; como ejemplo la gran minería no contamina (con alguna excepción) hoy en día, pues la censura global difícilmente lo permitiría además de la gran tecnología ambiental de punta que han desarrollado muchas empresas; sin embargo la tan predominante "contaminación" siempre será su talón de Aquiles aunque no exista. La realidad es que una transnacional no está en la capacidad de ofrecer trabajo a toda la población o al menos a gran parte de ella, por ello la única manera de evitar conflictos socio ambientales es la ejecución de proyectos de desarrollo sostenible en donde la población tendrá necesariamente que estar involucrada y ser artífice de su propio destino, caso contrario siempre habrán conflictos sociales en detrimento del país y de la misma población en términos generales. Muy pocas empresas en realidad han podido lograr una verdadera convivencia pacífica mediante el desarrollo de proyectos, ello nuevamente nos trae a colación la tan notoria carencia de mayores cuadros profesionales especialistas en el tema.

Hoy en día es imposible que un país pudiera aislarse del resto en un mundo globalizado y altamente competitivo, todos los países necesitan inversiones, aún los del primer mundo; no se puede ir en contra de dicha mega tendencia, la clave está en que dichas inversiones y flujos de capital deberán darse de manera socialmente responsable en donde deberá primar el equilibrio económico, ambiental y social a fin de alcanzar el tan anhelado desarrollo sostenible. El compromiso de hacer las cosas bien desde un comienzo será la clave para alcanzar los objetivos propuestos a los que la educación no puede ser en absoluto ajena, pues la única manera en que un país puede lograr ser competitivo y salir del subdesarrollo como es el caso de gran mayoría de países latinoamericanos es mediante ella, desde el nivel inicial; un país es el reflejo del gran porcentaje de su población, por tanto, no puede existir democracia si no hay un buen nivel de educación. Ahora más que nunca la formación profesional debe poseer un carácter internacional, global, capaz de hacer pensar con mentalidad mundial para actuar nacional y localmente; además, las herramientas gerenciales, de administración de negocios y liderazgo deberán estar inmersas dentro de toda carrera profesional en el país y en el mundo entero dado que las exigencias globales así lo demandan. Insistimos que los cambios se dan por necesidad y no por ideas.

\section{ANÁLISIS DE LA SITUACIÓN ACTUAL}

La situación actual en el caso del Derecho Ambiental no es muy alentadora, si bien existe hoy en día un pleno conocimiento de esta rama del derecho además 
de saber que nos encontramos en el siglo ambiental, aún tiene primacía el estilo jurídico tradicional en el mismo, lo que ha conllevado a la inviabilidad de la aplicación del Derecho Ambiental; aún no logramos entender la necesidad que la dinámica ambiental debe ser tratada de manera interdisciplinaria, acudiendo a otras ramas inclusive ajenas al campo del Derecho, a fin de hacer sinergia y tomar correctas decisiones ambientales antes que buenas o malas. Dada tal situación actual con respecto a la moda ambiental, muchos profesionales aún optan por inmiscuirse en el tema sin la debida capacitación y/o especialización, sin herramientas, sin experiencia laboral ambiental, sin haber desarrollado el tino para enfrentar los diversos problemas ecológicos, sin el ánimo de trabajar en equipo para objetivos comunes, sin compromiso para ser socialmente responsables, sin conciencia socio ambiental. Todavía no se han creado juzgados ni jueces especialistas en medio ambiente, los problemas ambientales son vistos desde una perspectiva del Derecho Civil y penal únicamente. Fiscalías en materia ambiental han sido creadas, el problema ha surgido en que gran mayoría de abogados nombrados fiscales ambientales no son especialistas, por tanto, volvemos a la misma inviabilidad del Derecho Ambiental en el país, el cual está siendo manejado desde una perspectiva netamente positivista y tradicional.

En el ámbito educativo, algunas universidades aún no han incorporado la temática ambiental en sus currículos y no le dan la debida importancia; muchas otras, designan docentes con el ánimo de distribuir cargas académicas sin tener en cuenta si es que el docente presenta experiencia, conocimiento o calificación ambiental para desarrollar la cátedra universitaria. Diversos eventos y congresos ambientales son llevados con cierta periodicidad; ocurre que muchas veces igualmente, algunos expositores podrían ser especialistas en el tema, sin embargo jamás han desarrollado actividades socio ambientales fuera de las aulas universitarias o en el campo, situación que no causa la eficacia ni efectividad en cuanto a la correcta capacitación ambiental. A pesar de haberse llegado a diversos consensos en cuanto a que el tema de responsabilidad social debe ser llevado en todos los currículos de todas las profesiones sin excepción alguna, éste ha quedado únicamente en pura teoría y buen entusiasmo ya que en la práctica casi ninguna universidad en el país presenta el curso de responsabilidad social en sus diversos planes de estudio. Lo mismo en el sector público educativo, las prácticas ambientales si bien muchas veces están plasmadas en los libros y textos, éstos no son fomentados ni aplicados por los maestros ni mucho menos por los estudiantes de todos los niveles educativos.

En los últimos años y con mayor énfasis en la actualidad somos testigos de la problemática socio ambiental que caracteriza y aqueja al país, al extremo que la extracción de los recursos naturales estén condicionados a la aceptación de la población y comunidades mediante la llamada "licencia social". La responsabilidad social debiera en primer lugar ser asumida por el Estado en 
conjunción con las instituciones que existen en el país de la misma manera en que todo ser humano debe ser socialmente responsable. La realidad peruana demuestra que muchas veces la no presencia del Estado en ciertos lugares del país ocasiona que sean las mismas empresas las que deberán asumir el papel que corresponde al Estado siendo ésta la única manera de lograr una convivencia pacífica entre empresa y comunidad.

\section{ANÁLISIS DEL FUTURO}

Diversos eventos han debido acontecer para aceptar y llegar a entender que si bien el cambio es difícil, éste representará el éxito en las buenas prácticas social y ambientalmente responsables. La preparación interdisciplinaria en los profesionales que enfrenten los desafíos en el siglo XXI será decisiva; el Estado, las empresas y las universidades jugarán el rol más importante con miras a tales desafíos actuando como aliados estratégicos. Tendremos que apostar por un nuevo modelo profesional empezando desde cero y teniendo en cuenta los errores cometidos en el pasado en cuanto a los asuntos socio ambientales. Las empresas irán asimismo tomando mayor conciencia en la preparación profesional idónea a fin de contar con los mejores cuadros para ser enrolados en sus filas corporativas; la calidad de la empresa demuestra la calidad de los trabajadores, por tanto, será cada vez más latente la necesidad de incorporar al mejor recurso humano a fin de conseguir los resultados empresariales trazados. Asimismo, la experiencia de los profesionales con mayor trayectoria prevalecerá sobre la de muchos jóvenes entusiastas, pues de hecho que las vivencias y los años profesionales logrados por muchos representan una herramienta muy valorable y necesaria.

Una vez más, las casas de estudio deberán reafirmar su compromiso de mantener la formación de profesionales altamente capacitados y calificados capaces de interactuar en el mundo globalizado de acorde a las exigencias de los perfiles profesionales del siglo XXI, en donde el involucramiento de autoridades, docentes, estudiantes y padres de familia seguirá siendo el sostén de la excelencia rumbo al desarrollo de la ciudad, de la región y del país.

\section{CONCLUSIONES Y RECOMENDACIONES}

- Urge un mayor número de especialistas en Derecho Ambiental por parte de muchos abogados en el país.

- El carácter multidisciplinario en la misma reviste la piedra angular de la materia.

- La experiencia minera en el Perú juega un rol primordial en la formación de los abogados ambientalistas.

- La tecnología impacta también al Derecho, el Derecho Ambiental no es ajeno a ello en absoluto. 
- El Derecho Ambiental y la experiencia de campo van de la mano.

- El enfoque ambiental global debe ser adecuado a cada realidad a fin de hacerlo eficaz.

- Los asuntos socio ambientales serán trascendentales durante todo el siglo XXI, más aún en un país muy rico en recursos naturales como lo es el Perú y que demanda profesionales especialistas en el tema.

\section{BIBLIOGRAFÍA}

1. Claverías, Ricardo, “Desarrollo Territorial y Nueva Ruralidad en el Perú”, Lima: Experiencias y propuestas del CIED, 2007, página 95.

2. Manrique, Guillermo: “A Demandas Sociales Respuestas Sociales", Revista Minería, 42 (2006), pagina.37.

3. Manrique, Guillermo: "Paradigmas Sociales Dominantes de la Minería", Revista Minería, 35 (2005), pagina .28.

4. Manrique, José Carlos, "El Abogado en el Siglo XXI”, Filosofía y Derecho, 10 (2004), pagina.1. 